\title{
Sobre los alcances del objeto contractual en el diseño del Código Civil de 1984
}

\section{Marco Antonio Ortega Piana}

\section{Introducción}

El presente trabajo está orientado a dejar constancia de una determinada posición sobre cuál es el objeto contractual conforme con el Código Civil peruano (1984). El propósito es evidenciar qué es lo que se habría representado el legislador en el proceso de codificación que concluyó en 1984. Dado que en las aulas y en el ejercicio profesional muchas veces adoptamos como propias las que son simplemente interpretaciones ajenas, sin compulsarlas con ciertos antecedentes, este trabajo reclama, finalmente, que el lector asuma una posición sobre el tema. Con ello, sentiremos que su objeto ha sido alcanzado. Toda discrepancia será bienvenida, porque generará en última instancia un punto de encuentro en el camino para alcanzar un conocimiento más informado.

En ese sentido, se postula que, según el diseño legislativo nacional, los contratos no solo tienen como objeto las obligaciones -en cuanto relaciones jurídicas patrimoniales específicas-, sino que, en función de ello, no es posible sostener que en materia de transferencia convencional de propiedad nos encontremos ante un sistema mixto o dual. Conforme a este sistema, en la transmisión convencional de propiedad inmobiliaria, nos sujetamos a un régimen con efectos traslativos, mientras que, en la transmisión mobiliaria, estamos ante un régimen con efectos crediti- 
$\operatorname{cios}^{1}$. En consecuencia, sobre la base de la norma-eje que representa el artículo 1402 del Código Civil, debe concluirse que todo contrato es obligacional y que, de manera correlativa, en materia de transferencia convencional de propiedad, nos adscribimos a la denominada teoría del título y el modo, por lo que, según ello, deben ser leídos y aplicados los artículos 947 y 949 del Código Civil.

Cuestión distinta es el juicio que cada quien está llamado a realizar sobre si la regulación legislativa del objeto contractual es la más idónea para fines del tráfico jurídico, si genera o no la necesaria seguridad; dado que, como toda opción legislativa, es susceptible de crítica y perfeccionamiento. Pero esa evaluación debe partir de algo cierto: identificar qué es lo que se representó el codificador nacional al regular de una determinada manera el objeto contractual, puesto que tuvo ante sí diversos modelos legislativos. Sin embargo, se puede sostener que no ha habido estrictamente un legislador, sino legisladores, y que estos últimos se han sucedido en el tiempo, porque una cosa es el diseño legislativo bajo la denominada Comisión Reformadora ${ }^{2}$ y otra bajo la Comisión Revisora ${ }^{3}$. Pero, en cualquier caso, no se debe asumir que el

1 Resulta difícil negar que ello se desprende, al menos textualmente, de los artículos 947 y 949 del Código Civil, ya que, en materia mobiliaria, la regla general de transferencia radica en que debe mediar entrega del bien por parte del transferente al adquirente (debe cumplirse con la obligación de entregar); en cambio, en materia inmobiliaria, por la sola obligación de enajenar, el adquirente se hace propietario del respectivo bien cierto (no habría obligación alguna que cumplir).

2 La denominada Comisión Reformadora fue creada mediante el Decreto Supremo 95 del 1 de marzo de 1965, expedido durante el primer gobierno constitucional del presidente Fernando Belaunde Terry. A los miembros de dicha comisión se les encargó el estudio y revisión del Código Civil de 1936, esto es, cuando el mismo no había cumplido ni siquiera treinta años de vigencia. Entre sus miembros más renombrados estaban, en un primer momento, Carlos Fernández Sessarego, José León Barandiarán, Rómulo Lanatta Güilhem, Héctor Cornejo Chávez y Max Arias-Schreiber Pezet; de manera posterior se integraron Felipe Osterling Parodi, Jorge Avendaño Valdez, Lucrecia Maisch von Humboldt, Manuel de la Puente y Lavalle, y Fernando de Trazegnies Granda, entre otros renombrados juristas. Si bien el encargo inicial fue proponer las modificaciones necesarias al Código Civil de 1936, sus miembros optaron finalmente por elaborar y proponer un texto sustitutorio, un nuevo Código Civil. Los trabajos de esta comisión se extendieron hasta 1981, cuando se presentó al Poder Ejecutivo (segundo gobierno constitucional del presidente Fernando Belaunde Terry) el respectivo proyecto.

3 La Comisión Revisora fue creada por la Ley 23403, promulgada en mayo de 1982, y tenía precisamente por objeto revisar el denominado primer proyecto o proyecto elaborado por la Comisión Reformadora. Entre sus miembros más destacados 
sentido de la legislación es aquello que postulamos hoy en día, muchas veces más influenciados por lecturas foráneas que considerando las razones por las que el Código Civil contiene ciertas reglas, y no otras como se quisiera.

Atendiendo a lo expuesto, somos de la opinión de que carece de adecuado fundamento proponer interpretaciones sustentadas en una mera literalidad, o tomar como concluyente lo que puede ser válido bajo otras legislaciones, por más que hubiesen inspirado de alguna manera a los textos nacionales. Como todo en la vida, hay que regresar a los orígenes para dimensionar adecuadamente el sentido de lo actual, y bajo esa comprensión proyectarnos al futuro.

En ese contexto, adquieren más vigencia que nunca las palabras del maestro Manuel de la Puente y Lavalle (2011), contenidas en la parte final de su magna obra El contrato en general, cuando manifiesta:

No quiero terminar esta obra sin expresar una preocupación que me desasosiega. Pese a considerar que la Sección Primera del Libro VII del Código Civil constituye un excelente conjunto de disposiciones que de manera coherente profundiza con responsabilidad la problemática de la contratación moderna, debo reconocer que, como toda factura humana, adolece de defectos que afean la obra legislativa. Frente a estos incuestionables defectos, existe una corriente de opinión que, no obstante su loable mérito en destacarlos, se orienta a corregirlos mediante la modificación o supresión de las normas jurídicas correspondientes. Pienso que debemos afrontar una realidad. Los Códigos no son una secuencia de disposiciones colocadas caprichosamente unas al lado de las otras, sino un todo orgánico en que cada una de sus normas, especialmente las que integran cada Sección, responde a un plan integral que las vincula íntima y ordenadamente, de tal manera que el cambio o supresión de una de ellas rompe la armonía del conjunto. Como los Códigos no pueden sustituirse rápidamente, pues son redactados con una vocación de permanencia, pienso que el camino adecuado es tomar una actitud

figuraban Javier Alva Orlandini, Roberto Ramírez del Villar, César Fernández Arce y Jack Bigio Chrem. Su competencia fue complementada mediante la Ley 23756, promulgada en diciembre de 1983. Los trabajos de esta comisión se extendieron hasta julio de 1984, cuando se presentó al Poder Ejecutivo el respectivo proyecto (que bien puede ser llamado segundo proyecto, elaborado sobre la base del primero entregado en 1981). 
más positiva e intentar la interpretación de la norma cuestionada utilizando especialmente los medios o elementos lógico y sistemático, para otorgarle su verdadero sentido a través de su relación con las demás en su conjunto. Sólo así lograremos conservar nuestro Código de acuerdo a la concepción que lo inspiró, adecuando meditadamente su espíritu a la constante evolución del Derecho, sin restarle coherencia y unidad. Es admirable, en este sentido, la jurisprudencia francesa que ha logrado actualizar el viejo Código Napoleón, sin necesidad de recurrir a cambios legislativos superables.

Únicamente si se detectan verdaderos errores conceptuales innatos, que resulten insalvables de otro modo, será menester tomar el duro camino de la modificación radical. De igual manera, esa medida deberá tomarse si el devenir nos depara tales cambios ideológicos en la noción del Derecho contractual que la reestructuración de su manifestación positiva sea inevitable para adecuarse a la nueva realidad. (pp. 667-668)

Por último, pero no por ello menos significativo, debemos expresar nuestro agradecimiento a Ius et Praxis, revista oficial de la Facultad de Derecho de la Universidad de Lima, por la publicación de este trabajo con ocasión de su edición dedicada al trigésimo aniversario del Código Civil (1984).

\section{Sobre el objeto contractual}

Para comenzar, debemos precisar lo que entendemos por objeto contractual. De las diversas acepciones que la palabra objeto tiene en nuestro idioma (Real Academia Española, 2014), dos pueden resultar pertinentes para este trabajo. De un lado, objeto es el fin o propósito a que se dirige o encamina una acción u operación; de otro, objeto es simplemente una cosa, un bien material.

Es relevante traer a colación el significado del término recogido por el Diccionario de la lengua española, porque no se puede olvidar que los lenguajes comunes, académicos y legislativos no son necesariamente coincidentes (Alterini, Corna, Angeliani y Vásquez, 2000, pp. 1-7). Algunas veces nos encontramos ante torres de Babel más aparentes que reales, dado que no realizamos el esfuerzo para identificar el sentido de nuestro lenguaje y el ajeno. 
El lenguaje común es simplemente el cotidiano, comprensible para las mayorías, para todos los miembros de una colectividad. El lenguaje académico corresponde a una aspiración de mayor precisión. Es técnico para los fines de la ciencia jurídica; en consecuencia, no necesariamente es comprensible para todos. Y el lenguaje legislativo tiene alcances especiales. Debe ser comprensible en general, pero tampoco debe alejarse de la rigurosidad jurídica. El problema es que muchas veces leemos lo legislativo como si fuese un lenguaje académico, y no es así definitivamente. El lenguaje legislativo debería estar más identificado con el cotidiano, salvo en aquellos aspectos en los que resulte indispensable la precisión académica. Por ello, se postula que el lenguaje legislativo debe ser sencillo y comprensible, ajeno a interpretaciones sutiles.

Así, Montesquieu afirmaba:

El estilo debe ser conciso [...], debe ser sencillo; la expresión directa se comprende mejor que la figurada [...]. Es de esencia que las palabras de las leyes despierten en todos las mismas ideas [...]. Las leyes no deben ser sutiles, se hacen para gentes de mediano entendimiento; no son un arte de lógica, sino la simple razón de un padre de familia [...]. Es menester procurar que las leyes no estén concebidas de manera que pugnen con la naturaleza de las cosas [...]. (Como se citó en Alterini et al., 2000, p. 6)

Según lo expresado, debe realizarse el esfuerzo de discernir a qué se ha referido el legislador nacional al regular el objeto contractual. Si bien uno puede sostener que el objeto (fin) debe ser lícito, también podría señalarse muy válidamente que el objeto (cosa) debe ser determinado o determinable, o existente, o con posibilidad de existencia. Todos sabemos que los términos pueden ser polisémicos, como bien destaca Roppo (2009), de manera que en lo jurídico una misma palabra puede tener significados distintos, como ocurre al tratarse de dolo en materia de acto jurídico, de inejecución de obligaciones voluntarias y de responsabilidad civil (pp. 43-44).

Lo que sostenemos es que, para fines del Código Civil (1984), objeto contractual es sinónimo de aquello que las partes pretenden jurídicamente; se identifica con su propósito, pero se considera también la perspectiva de que hay de por medio un interés relevante o merecedor de tutela. Y, sobre dicha base, el legislador ha sido consistente en enunciar el atributo que debe revestir ese objeto, diferenciándolo claramente 
de los atributos relativos o propios al contenido de ese objeto. Este entendimiento no fluye de uno $\mathrm{u}$ otro artículo, entre cientos que conforman el Código Civil, sino que se aprecia en una lectura serena y sistemática de este último. Estamos ante una noción que atraviesa ciertamente a todo el Código Civil 4 .

A diferencia de otras regulaciones, que omiten hacerlo y que se limitan a enunciar las características del objeto contractual, el Código Civil (1984) contiene innovadoramente en nuestra tradición civilista una definición de lo que es el objeto del contrato -que se encuentra en su artículo 1402-, la misma que por elemental criterio de especialidad prima sobre cualquier otra disposición que pudiese considerarse como pertinente. El artículo 1402 del Código Civil (1984) establece: “El objeto del contrato consiste en crear, regular, modificar o extinguir obligaciones". Así pues, por declaración expresa, el objeto de todo contrato es obligacional, esto es, el respectivo acuerdo de voluntades busca, pretende o tiene como propósito crear, regular, modificar o extinguir obligaciones, las mismas que son una especie dentro del vasto género de las relaciones jurídico-patrimoniales.

Y, conforme analizaremos, no estamos ante una simple definición, sino que esta representa conscientemente una determinada toma de posición. No se trata, por consiguiente, de una mera fórmula que sigue la tradición jurídica -como si esta última fuese invariable, fruto virtual de una suerte de revelación divina y que constituye el fundamento del conocimiento jurídico-, sino que estamos ante una determinada opción por la que se inclinó el legislador nacional ${ }^{5}$. Como veremos, el codificador de 1984 pudo omitir incorporar una definición, o bien pudo considerar una distinta, dado que, en palabras de Gabrielli (2013), se

4 Así, por ejemplo, los debates jurídicos sobre la naturaleza jurídica del contrato sobre hecho ajeno, o sobre el acuerdo de opción, en nuestro sistema legal, se simplifican tremendamente si partimos de un común entendimiento de que el objeto del contrato solo puede ser legalmente uno: relaciones obligacionales, con todo lo que se desprende de ello: contenido gestacional, conducta posible en cabeza del deudor, quien es parte material de la respectiva relación contractual.

5 Legislar implica optar. Nos remitimos a un caso, entre tantos, en el ámbito contractual. En su momento, ante la posibilidad de regular que se trataba de un negocio anulable o rescindible, y según expresa el profesor Jack Bigio, el codificador se inclinó por esto último al tratarse de la venta de bien ajeno. El fundamento fue simplemente pragmático: en qué consiste la carga probatoria y cuál es el plazo para accionar, conforme se destaca nada menos que en la Exposición de Motivos Oficial del Código Civil. 
está ante una materia "muy debatida y controvertida" (p. 266), pero acogió finalmente una bastante puntual y concreta, sobre la base de su concepción -más allá de que esta sea correcta o no- de que el contrato pretende satisfacer un determinado interés.

La cuestión radica en que se intenta oponer dicha regla, prácticamente silenciándola, respecto al artículo 1351 del Código Civil, que también representa una innovación del código vigente. Este artículo -entre las disposiciones generales contenidas en la Sección Primera (Contratos en general) del Libro VII (Fuentes de las Obligaciones) del referido cuerpo normativo- define lo que es un contrato, y se otorga una preeminencia a esta última norma. El artículo 1351 del Código Civil (1984) establece: "El contrato es el acuerdo de dos o más partes para crear, regular, modificar o extinguir una relación jurídica patrimonial".

No hay duda alguna de que un contrato es un acuerdo de voluntades que implica un consentimiento, un querer común, lo cual es admitido pacíficamente por la doctrina. Tampoco hay duda de que un contrato tiene incidencia en el ámbito patrimonial en general, ya que lo extrapatrimonial no está sujeto propiamente a reglas que se sustentan esencialmente en la voluntad privada, sino en otras consideraciones. Así, por ejemplo, el acuerdo matrimonial, por más que sea voluntario, no es estrictamente un contrato. Es mucho más que un contrato: corresponde a una institución social y se asocia a una determinada manera de enfocar las relaciones humanas, inclusive desde la perspectiva del derecho natural.

Nuestra tesis radica en distinguir entre un enunciado general sobre lo que es un contrato, y un enunciado específico sobre lo que puede versar un contrato. Relación jurídica patrimonial no es sinónimo de obligación; incluye a esta última, pero es más que ella. Sin embargo, no podemos obviar que el tema puede ser más complicado de lo que parece a simple vista. El artículo 1351 del Código Civil (1984) tiene una redacción que es coincidente, palabras más o palabras menos, con la contenida en el Código Civil italiano de 1942, el mismo que constituyó ciertamente una de las grandes fuentes de inspiración del legislador nacional.

En efecto, el artículo 1321 del Codice expresa lo que es su noción legislativa de contrato: “El contrato es el acuerdo de dos o más partes para constituir, regular o extinguir una relación jurídica patrimonial entre ellas". No podemos negar que el texto legislativo nacional es prácticamente una reproducción del texto italiano. En función de ello, cabe 
preguntarse si hacemos nuestros los desarrollos jurisprudenciales y doctrinarios italianos sobre el particular o no. Y dejamos constancia de que está fuera de toda discusión el nivel de desarrollo e influencia alcanzado progresivamente por la doctrina italiana en materia jurídica.

Postulamos que no corresponde hacer nuestros los señalados desarrollos, porque la conceptualización de lo que es un contrato tiene determinada orientación en el sistema civil italiano, que es completamente ajena a lo que se representó y propuso el legislador nacional y a lo que representa nuestra tradición jurídica. En otras palabras, una coincidencia (porque eso es, una coincidencia) no implica que los alcances jurídicos del objeto contractual conforme con la legislación peruana deban ser asimilados a los de la legislación italiana. Recordemos que en materia de interpretación, más allá de que sea legal o contractual, lo literal es lo básico o elemental ${ }^{6}$; una interpretación será más consistente en la medida en que incorpore otros criterios para dilucidar los alcances del respectivo texto. Asimismo, para fines de dicha interpretación, no olvidemos la reflexión e invocación de De la Puente y Lavalle (2011):

Los Códigos no son una secuencia de disposiciones colocadas caprichosamente unas al lado de las otras, sino un todo orgánico en que cada una de sus normas, especialmente las que integran cada Sección, responde a un plan integral que las vincula íntima y ordenadamente [cursivas añadidas], de tal manera que el cambio o supresión de una de ellas rompe la armonía del conjunto. Como los Códigos no pueden sustituirse rápidamente, pues son redactados con una vocación de permanencia, pienso que el camino adecuado es tomar una actitud más positiva e intentar la interpretación de la norma cuestionada utilizando especialmente los medios o elementos lógico y sistemático, para otorgarle su verdadero sentido a través de su relación con las demás en su conjunto [cursivas añadidas]. Sólo así lograremos conservar nuestro Código de acuerdo a la concepción que lo inspiró,

6 Sobre este tema, Roppo (2009) expresa: "Punto de partida es la interpretación textual, que se basa en el significado expreso de las palabras del texto y de sus conexiones sintácticas, según el código lingüístico compartido por la comunidad de hablantes a la que pertenecen los contratantes: a ella el intérprete no debe 'limitarse', pero por ella debe sí pasar [cursivas añadidas]. La interpretación textual puede dejar márgenes de duda o ambigüedad semántica (cierta palabra puede tener dos diversos significados, ambos compatibles con el código lingüístico de referencia): en tal caso, es natural -más bien indispensable- dirigirse a la búsqueda de la efectiva 'común intención' de las partes, mediante datos extratextuales' (p. 440). 
adecuando meditadamente su espíritu a la constante evolución del Derecho, sin restarle coherencia y unidad [cursivas añadidas]. (pp. 667-668)

Atendiendo a lo expresado con anterioridad, inclusive en la hipótesis de que el legislador nacional hubiese pretendido reproducir el texto de la definición italiana de contrato, lo cierto es que ello no implica necesariamente que la respectiva norma deba ser leída e interpretada como se hace en otras latitudes. Por el contrario, su lectura e interpretación debe realizarse en función de lo que el codificador peruano se representó en el marco de su regulación sobre contratos. Es más, como se propone en el presente trabajo, considerando que el Código Civil de 1984 es finalmente una unidad legislativa, esa lectura e interpretación también debe tomar en cuenta lo que el codificador se representó, entre otros aspectos, en materia de derechos reales ${ }^{7}$ y en los diversos tipos de los contratos de cambio $^{8}$, en todo lo cual se aprecia una nota común: generación de obligaciones.

En tal virtud, si se pretende oponer el artículo 1351 del Código Civil (1984) a lo establecido en su artículo 1402, y sin necesidad de que deba invocarse el argumento lógico según el cual la norma especial debe pre-

7 Sobre esto, resulta pertinente tener presente que, en la lectura de los proyectos del Código Civil tanto de la Comisión Reformadora como de la Comisión Revisora, se aprecia que el codificador siempre se representó el régimen del título y el modo, según el cual el título es el contrato y el modo es el medio de ejecución de lo acordado en dicho contrato para que el transferente pueda efectivamente trasladar la propiedad al adquirente (De la Puente, 1999, p. 69).

8 Sobre la base de que los contratos de cambio son aquellos relativos a la transferencia de propiedad, es decir, a la enajenación de bienes, los artículos 1529, 1602 y 1621 del Código Civil (1984) establecen respectivamente lo siguiente: "Por la compraventa el vendedor se obliga a transferir [cursivas añadidas] la propiedad de un bien al comprador y éste a pagar su precio en dinero", "Por la permuta los permutantes se obligan a transferirse [cursivas añadidas] recíprocamente la propiedad de bienes" y "Por la donación el donante se obliga a transferir [cursivas añadidas] gratuitamente al donatario la propiedad de un bien".

De otro lado, en el caso del contrato de suministro, el artículo 1604 del Código Civil sanciona su carácter obligacional, que si bien no hace mención expresa a que el suministrante se obliga a entregar en propiedad, periódica o continuadamente, bienes a favor del suministrado, ello se colige sistemáticamente del artículo 1609 del mismo cuerpo normativo. Y, en el caso del contrato de mutuo, si bien el artículo 1648 del Código Civil también sanciona (como no podía ser de otra manera) su carácter obligacional, en lo que se refiere a la obligación de transferir la propiedad se está a lo dispuesto en su artículo 1654, en el sentido de que la obligación de entregar es para fines de transferir la respectiva propiedad. 
dominar sobre la general -en la medida en que hubiese incompatibilidad entre ellas (lo cual negamos)-, lo mínimo que se espera es revisar qué explica el actual tenor de la definición legislativa de contrato (artículo 1351 del Código Civil), ya que solo así se podría proponer una lectura consistente con lo contenido en su artículo 1402.

En el extenso proceso de elaboración del Código Civil (1984), el tenor actual del artículo 1351 sufrió diversas modificaciones, que fueron de forma antes que de fondo. De manera sintética, se puede sostener que no es posible afirmar que bajo la expresión relación jurídica patrimonial el codificador nacional se representara lo que sí hizo en su momento el codificador italiano, dado que este último no exige que el contenido contractual sea obligacional para que pueda, en esos términos, generarse un sistema de transferencia convencional de propiedad espiritualizado, esto es, uno según el cual por el simple acuerdo de voluntades se transfiere (relativamente) la propiedad del bien sobre el cual recae el consentimiento, por el mérito del contrato mismo. Pero, en nuestro caso, más allá de la coincidencia de redacción, el legislador nacional no se representó dicho régimen de transferencia, sino que identificaba simplemente lo patrimonial con lo obligacional. Inclusive, en cierto momento se estableció que el contrato era un acuerdo obligacional de carácter patrimonial (definición redundante, por decir lo menos), cuando era suficiente haber señalado que era un acuerdo patrimonial, más allá de que luego se precisase que, dentro de dicha patrimonialidad, el objeto (esto es, lo que se proponen las partes) es la creación, regulación o extinción de obligaciones, y no otra clase de relaciones jurídicas.

Para ello, es pertinente tener en cuenta que, de acuerdo con el anteproyecto (1980) de la Comisión Reformadora, propuesto por el profesor Max Arias-Schreiber, en materia de Fuentes de las Obligaciones, su artículo 1 sancionaba lo siguiente: "El contrato es el acuerdo de dos o más partes para crear, regular o extinguir entre sí obligaciones de carácter patrimonial". Dicho texto quedó, siempre en el ámbito de la Comisión Reformadora, en el artículo 1370 del respectivo proyecto (1981) según lo siguiente: "El contrato es el acuerdo de dos o más partes para crear, reglar, modificar o extinguir entre sí obligaciones de carácter patrimonial".

En otras palabras, en el ámbito de la Comisión Reformadora, la representación del legislador sobre lo que es un contrato no era sino la de un acuerdo obligacional, con carácter (por consiguiente) patrimo- 
nial. El propio Arias-Schreiber (1995) lo destaca en su obra Exégesis... cuando manifiesta:

Aunque la mayoría de los Códigos no definen y dejan esta materia a los tratadistas y docentes, el Código vigente, fiel a su concepción pedagógica, lo ha hecho y señala en el artículo 1351 que es el acuerdo destinado a crear, regular, modificar y extinguir una relación jurídica de carácter patrimonial, es decir, una relación obligatoria [cursivas añadidas]. (pp. 43-44)

Podremos estar de acuerdo o no con el sentido de la definición, ya sea sobre la base de nuestro entendimiento de si correspondía o no introducir la señalada definición, o sobre sus alcances; pero no podemos negar que para el codificador (al menos en el ámbito de la Comisión Reformadora) la mención de la relación jurídica patrimonial era sinónimo de relación obligacional (por lo menos, para fines del objeto contractual). En otras palabras, para el legislador nacional, el contrato se asocia necesariamente a obligaciones. Y si el contrato es el título que permite una ulterior transferencia convencional de propiedad, bien puede concluirse que para lograr esta última se requiere de la observancia de un modo o manera para alcanzarla, que sería finalmente la conducta esperada a cargo del deudor de la transferencia. En consecuencia, la propiedad no es transferida por el mérito de la sola celebración del contrato, sino porque se ejecuta la prestación que constituye el contenido material de la obligación generada por la celebración del contrato, más allá de que dicha ejecución provenga del propio deudor o lo disponga la ley, superponiéndose a este último9.

¿Por qué el codificador de la Comisión Reformadora consideraba que relación jurídica patrimonial era lo mismo que relación obligacional?

No debe olvidarse que, en materia de obligaciones, el interés es la noción matriz que permite dar sentido funcional al contenido de la respectiva relación jurídica (Bianca, 1994, p. 45). Las obligaciones, como relaciones jurídicas, se estructuran sobre la base de un determinado interés: el de una parte (acreedor) que pretende algo que está al alcance, en la esfera patrimonial, de

9 Situación que corresponde a lo establecido en el artículo 949 del Código Civil (1984), y que deriva en el cuestionamiento de si hay realmente prestación o no, dado que el deudor no ejecuta nada, ya que la transferencia inmobiliaria opera ministerio legis; empero, esa situación no significa que no hay una prestación por ejecutar, sino cómo se ejecuta. 
su contraparte (deudor), siendo la prestación aquello que se pretende mediatamente, más allá de que sea de ejecución positiva (dar, hacer) o negativa (no hacer). Dado que las obligaciones pueden ser de fuente autónoma (voluntaria) o heterónoma (legal), el medio ordinario para generarlas es el acuerdo de los interesados, de manera que todo contrato es literalmente instrumental. No solo porque sirve para fines del tráfico de bienes y servicios, dotándolo de seguridad, sino porque lo que pretende inmediatamente es instituir una determinada clase de relación jurídica; o si la misma ya existe, regularla o extinguirla.

Atendiendo a dicha consideración, en el ámbito de la Comisión Revisora, se acordó finalmente, en el artículo 1318 del proyecto publicado en febrero de 1984 (segundo proyecto, si se compara con el publicado por la Comisión Reformadora en 1981, que vendría a ser el primer proyecto), lo siguiente: "El contrato es el acuerdo de dos o más partes para crear, regular, modificar o extinguir una relación jurídica patrimonial". Ese es el texto que corresponde al artículo 1351 del Código Civil (1984) vigente.

Para quienes sostienen que el artículo 1351 del Código Civil peruano (1984) se inspira en la legislación italiana y debe ser aplicado en ese contexto, hay cierto detalle que no puede obviarse. Dado que el codificador nacional, tanto en la Comisión Reformadora como en la Comisión Revisora, se representó el contrato como fuente de obligaciones, cuidó de introducir una definición expresa de lo que es el objeto contractual. El artículo 1402, por consiguiente, zanja (o debería zanjar) cualquier discrepancia sobre lo que es materia del acuerdo contractual, al establecer que debe ser obligacional.

Conforme a ello, el artículo 1351 del Código Civil (1984), no solo por razones de antecedentes en su proceso de redacción (que no deben dejarse de apreciar), sino por elemental cuestión sistemática, no puede ser leído e interpretado sin considerar los alcances del artículo 1402 del mismo cuerpo normativo. De la misma manera, dentro de los alcances de las transferencias derivadas de propiedad, el artículo 949 del Código Civil no debería ser interpretado al margen del artículo 1402 del mismo cuerpo legal.

El legislador nacional cuidó de enunciar explícitamente que el objeto de todo contrato (más allá de la manera en que pueda clasificarse, sea por su perfeccionamiento constitutivo, por su funcionalidad, por sus efectos, por su duración, etc.) es necesariamente obligacional. Enunciado que el Código Civil italiano no recoge porque -insistimos- parte de 
una premisa que no corresponde a nuestra legislación civil histórica ni a la voluntad uniforme del legislador.

En efecto, de acuerdo con el anteproyecto (1980) de la Comisión Reformadora en materia de Fuentes de las Obligaciones, su artículo 43 sancionaba: "El objeto del contrato consiste en crear, regular o extinguir obligaciones de dar, hacer o no hacer". Dicho texto quedó, siempre en el ámbito de la Comisión Reformadora, en el artículo 1418 del respectivo proyecto (1981), según lo siguiente: “El objeto del contrato consiste en crear, reglar, modificar o extinguir obligaciones de dar, hacer o no hacer".

Sobre la base de las premisas que explicaban esa redacción, el artículo 1367 del proyecto de la Comisión Revisora estableció: “El objeto del contrato consiste en crear, regular, modificar o extinguir obligaciones", texto que fue incorporado finalmente en el artículo 1402 del Código Civil (1984): “El objeto del contrato consiste en crear, regular, modificar o extinguir obligaciones". Sin embargo, se suprimió la indicación sobre el "dar, hacer o no hacer", porque, en rigor, corresponden al contenido de las prestaciones, que son las actuaciones debidas en función de la relación obligacional.

En otras palabras, tanto en la Comisión Reformadora como en la Revisora, y no obstante la diversidad de sus respectivas composiciones, la representación sobre lo que se pretende (objeto como sinónimo de fin o propósito común) con la celebración de un contrato era uniforme: se entendía que el objeto de todo contrato poseía definitivamente carácter obligacional.

Si el objeto es obligacional, resulta manifiesto que la relación jurídica patrimonial en que consiste un contrato (artículo 1351 del Código Civil peruano, 1984) no puede ser sino obligacional, pese a que lo patrimonial pudiese sugerir -textualmente- algo mucho más amplio (en el lenguaje académico, sin duda alguna). Hubiese sido probablemente lo más adecuado que, entre los artículos 1351 y 1402, hubiera absoluta simetría en la redacción, refiriéndose por igual a relaciones jurídicas obligacionales; empero, ello no autoriza a desconocer que ambas reglas fueron redactadas bajo un mismo entendimiento, un mismo espíritu. No olvidemos en todo caso que, conforme con el refrán ruso, lo perfecto es enemigo de lo bueno. Aunque no exista una coincidencia en el empleo de las palabras, lo importante es lo que hay detrás de estas últimas, para lo cual la interpretación de sus antece- 
dentes de redacción resulta fundamental, así como la interpretación sistemática del articulado del propio Código Civil.

Y, para que no quede duda alguna, el objeto contractual no solo se enuncia legislativamente en el artículo 1402 del Código Civil vigente, sino que, además, se reitera en su artículo 1403, cuando se diferencia inobjetablemente entre lo que es el atributo del objeto contractual (la obligación) y lo que son los atributos de esa conducta humana sobre la cual se posee interés relevante y digno de protección (la prestación). Se establece que la obligación debe ser acorde al ordenamiento jurídico (esto es, debe ser lícita), y se señala que la prestación debe ser posible, sin perjuicio - desde luego- de que además debe ser cierta (determinada o determinable) y estimable pecuniariamente.

Resulta pertinente remitirnos, nuevamente, a los textos que permiten apreciar qué es lo que se representó sucesivamente el codificador.

De acuerdo con el anteproyecto (1980) de la Comisión Reformadora en materia de Fuentes de las Obligaciones, sus artículos 44 y 51 sancionaban, respectivamente, lo siguiente: "La obligación que es objeto del contrato debe ser lícita", "La prestación materia de la obligación creada por el contrato debe ser posible". El tenor del artículo 44 quedó, siempre en el ámbito de la Comisión Reformadora, incorporado en el artículo 1419 del respectivo proyecto (1981), según lo siguiente: “La obligación que es objeto del contrato debe ser lícita". Se omitió regular lo concerniente a las características de la prestación, objeto material o contenido de la respectiva relación obligacional.

Por último, ya en el ámbito de la Comisión Revisora, se retomaron los artículos 44 y 51 de la referida ponencia del profesor Max Arias-Schreiber, y refundiéndolos se estableció lo siguiente en el artículo 1368 del proyecto de Código Civil publicado en febrero de 1981: “La obligación que es objeto del contrato debe ser lícita. El objeto de la prestación en que consiste la obligación debe ser posible". Dicho texto, palabras más o palabras menos, es el que figura actualmente en el artículo 1403 del Código Civil (1984): "La obligación que es objeto del contrato debe ser lícita. La prestación en que consiste la obligación y el bien que es objeto de ella deben ser posibles".

Se aprecia, en consecuencia, que el legislador de manera consistente -desde el anteproyecto Arias-Schreiber hasta la versión finalmente aprobada como Código Civil- elaboró un diseño normativo conforme al cual el objeto del contrato es la obligación. Y, como esta es una relación 
jurídica, la misma solo requiere ser lícita, siendo que el atributo de posibilidad (se entiende física) es propio de la actuación humana comprometida, esto es, de la prestación, que es la actividad en sí orientada a obtener el bien o servicio.

Hasta acá se ha realizado un recuento de antecedentes que forman parte del proceso de elaboración del Código Civil de 1984, el cual es más que ilustrativo; empero, puede considerarse que no arroja una conclusión definitiva, dado que el espíritu de la ley no se refleja necesariamente en su letra, sino que esta última adquiere cierta autonomía, ya que predomina lo expresado frente a lo querido. En ese sentido, resulta imperioso recurrir a otros criterios para fines de interpretación legal.

Sobre el particular, no se debe soslayar la explicación que proporciona De la Puente y Lavalle (2011) con relación a los alcances del objeto contractual bajo el Código Civil peruano (1984) y, por consiguiente, sobre la improcedencia de postular que dicho objeto no requiere ser obligacional (pese a la absoluta claridad, entre otros, de los artículos 1402 y 1403 del Código Civil), siendo suficiente que sea patrimonial (atendiendo a los alcances literales del artículo 1351 del Código Civil).

¿Por qué el Código Civil peruano (1984) establece que el objeto contractual, como sinónimo de propósito de las partes, de fin del negocio, debe ser obligacional?

El maestro Manuel de la Puente y Lavalle (2011) destaca, de un lado, que se quiso dejar explícita mención de lo siguiente: dado que todo contrato representa un instrumento, es decir, un vehículo de cooperación orientado a satisfacer determinado interés negocial, lo que las partes se representan y proponen -para fines de celebrar un contrato (función normativa ${ }^{10}$ : autorregulación de intereses)- es establecer una vinculación con el deudor, una determinada relación jurídica patrimonial, de tal manera que pueda exigirle cierta actividad. Exigencia en sentido estricto, por lo que, ante un incumplimiento, el acreedor podrá recurrir a los diversos remedios que están orientados a cautelar sus

10 "En realidad el negocio, y por lo tanto el contrato, nacen ya como actos normativos en el plano jurídico, por que [sic] los privados expresan, con el contrato, la potestad, atribuida a ellos por el ordenamiento, de crear normas jurídicas. El contrato nace como fuente de obligaciones, y es tal porque tiene naturaleza de fuente normativa. Si él crease vínculos solamente en el plano prejurídico, no sería un contrato" (Ferri, 2004, pp. vi-lvii). 
intereses ${ }^{11}$, los cuales se extienden desde la posibilidad de exigir el cumplimiento, de generarlo forzosamente, de obtener la ejecución debida por vías alternas, por cuenta del deudor, etc., hasta la posibilidad de optar (concurso electivo) por la resolución, sujeto esto último a los requisitos pertinentes. En otras palabras, esa determinada relación jurídica es una obligación, auténtica vinculación o encadenamiento del deudor al acreedor (De la Puente y Lavalle, 2011).

Y, de otro lado, se pretendió cerrar la discusión en nuestro medio sobre la posibilidad de configuración de contratos con efectos reales o traslativos, esto es, de aquellos que por el solo mérito de su celebración implican la transferencia de propiedad del bien materia del acuerdo (al margen de que sean muebles o inmuebles), puesto que el legislador nacional descartó la denominada espiritualización de la transferencia convencional de propiedad. Por lo tanto, la celebración de un contrato, inclusive tratándose de los acuerdos de cambio, al margen de su onerosidad o gratuidad, solo implica la generación de la obligación de transferir propiedad. De manera que hay un compromiso prestacional (el débito o deuda) que debe ser observado por el deudor en beneficio del interés del acreedor.

Aludiendo a la Exposición de Motivos y Comentarios, elaborada por los juristas que integraron la Comisión Reformadora ${ }^{12}$, en la que se diferencia claramente que una forma de entender el objeto contractual es que recae en la prestación, y otra, que recae en la relación jurídica (de la cual se desprende la prestación), habiéndose optado por esta última, De la Puente (2011) manifiesta:

[...] el legislador no siguió el cómodo camino de abstenerse de tomar partido y dejar a la doctrina la determinación del objeto del contrato, con todas las dudas y divergencias de opinión a que ello da lugar, sino que optó conscientemente, entre varias alternativas,

11 Resulta pertinente remitirnos a los artículos 1219 y 1428 del Código Civil, entre otros.

12 La Exposición de Motivos y Comentarios, de manera específica tratándose del libro Fuente de las Obligaciones del Código Civil, fue incorporada en la publicación de Delia Revoredo de DeBakey (como compiladora) bajo el título bibliográfico Código Civil (seis tomos), Lima, Perú, Okura Editores, 1985. En cuanto a la Sección Primera (Contratos en general) del libro Fuentes de las Obligaciones, la explicación exegética estuvo a cargo de Max Arias-Schreiber Pezet, con la colaboración de Carlos Cárdenas Quirós y Ángela Arias-Schreiber Montero. 
por una posición que, sin ser necesariamente indiscutible, consideró la más válida.

[...]

Se ha visto [...] que existen tres planteamientos sustentados por juristas de nota con plausibles razones, sobre el objeto del contrato, que unos ubican en la obligación, otros en la prestación y el resto en el bien o servicio.

Ante esta realidad, el codificador peruano, que bien pudo abstenerse de definir el objeto del contrato, o bien adoptar la posición de su homólogo italiano de limitarse a indicar que tal objeto debe ser posible, lícito, determinado o determinable, decidió elegir entre esos planteamientos y optó por el de considerar que el objeto del contrato es crear, regular, modificar o extinguir obligaciones. (p. 21)

Es más, atendiendo a los alcances ya comentados de los artículos 1351 y 1402 del Código Civil, prosigue:

Al comentar el artículo 1351 del Código Civil peruano, se vio que en todos sus antecedentes, hasta el artículo 1370 del primer Proyecto, inclusive, se habló de obligaciones de carácter patrimonial, y que sólo a partir del artículo 1318 del segundo Proyecto se empezó a hacer referencia a una relación jurídica patrimonial. Sin embargo, parece que esta modificación no se debió a un cambio de criterio sobre la finalidad del contrato como fuente de obligaciones, tan es así que tanto en el segundo Proyecto como en el Código civil se conservó el artículo referente a que el objeto del contrato es crear obligaciones.

Esto pone de manifiesto que para el codificador peruano la expresión "relación jurídica patrimonial" tiene un sentido distinto que le otorga el codificador y la doctrina italianos, o sea que se refiere a una relación obligacional [cursivas añadidas], con lo cual estoy de acuerdo.

Sin embargo, para evitar que al interpretarse el artículo 1351 se le dé un sentido distinto al que realmente tiene, el codificador peruano ha procedido bien al establecer que el objeto del contrato consiste en crear, regular, modificar o extinguir obligaciones, con lo cual ha eliminado la posibilidad de que se piense que el contrato puede producir efectos reales [cursivas añadidas]. (De la Puente y Lavalle, 2011, p. 21) 
Han transcurrido más de treinta años y pareciera, lamentablemente, que no caló de manera suficiente ese propósito explícito. Es más, cuando se genera el debate sobre el régimen de transferencia convencional de propiedad adoptado por el Código Civil (1984), a pesar de que el mismo presupone la existencia de un contrato, no se suele enmarcar dicho debate en función de las normas que regulan el objeto contractual y de lo que el legislador se representó; es tendenciosamente más cómodo quedarse con la definición general de contrato que permitiría respaldar la tesis del contrato traslativo, concordándola con la textualidad del artículo 949 del Código Civil.

A la fecha, subsiste la discusión sobre cuál es el objeto contractual conforme con la ley peruana y, para ello, se recurre a toda serie de argumentos, atendiendo sobre todo a la comparatística. Sin embargo, lo que llama la atención es que pareciera desconocerse lo que fue la ratio legis del artículo 1402 del Código Civil (1984). En primer lugar, todo contrato es un vehículo de cooperación intersubjetiva, por lo que busca generar una relación obligacional para que, en función de ella, el acreedor pueda exigir cierta prestación (conducta) al deudor, satisfaciendo su interés negocial. Y, en segundo lugar (y esto es lo concluyente), que se descartaba definitivamente la posibilidad jurídica de la generación de contratos con efectos reales, traslativos o espiritualizados, de manera que todo contrato de cambio genera exclusivamente efectos personales, crediticios $\mathrm{u}$ obligaciones. De ello se desprende que la transferencia de propiedad no se produce en etapa de celebración, sino de ejecución contractual, en la que se demanda una actuación por parte del obligado a transferir (más allá de que la ley la considere ejecutada, una vez celebrado el contrato, minimizando riesgos de incumplimiento, lo cual es ciertamente una situación excepcional).

Es más, al margen de la discusión académica que pueda mantenerse teóricamente sobre la materia (no olvidemos que hay de por medio un tema de opción del codificador de 1984), pareciera que se pone énfasis en la simple expresión, en la literalidad de las normas del Código Civil (1984), antes que, con "una actitud más positiva", postular una lectura sistemática que tenga en cuenta la orientación expresamente adoptada y que explique el uso de las palabras. Así, se sostiene, sobre la base del artículo 1351 del Código Civil, que es perfectamente posible un sistema espiritualizado de transferencia de propiedad, lo cual explica que el artículo 949 del mismo cuerpo nor- 
mativo no regule modo alguno, porque la celebración misma del contrato conllevaría la traslación de propiedad.

Entendemos y postulamos que las reglas legales sobre transferencia (convencional) de propiedad deben ser interpretadas y aplicadas en función de las reglas de contratos, dado que regulan las consecuencias de haberse celebrado un acuerdo de cambio, esto es, para fines de transferir titularidades sobre bienes, del derecho de propiedad. Conforme a ello, no se puede pretender que la consecuencia explique la causa; por el contrario, lo lógico es, más bien, que la causa explique la consecuencia.

El legislador peruano tuvo en sus manos el modelo legislativo italiano, lo replicó en muchos aspectos, pero en otros no, siendo que muchas figuras las acomodó a lo que bien se podría identificar como la tradición legislativa del país. El legislador nacional asumió un determinado régimen de objeto contractual. No resulta honesto que obviemos dicha decisión y tratemos de leer e interpretar el Código Civil (1984) como si contuviese un conjunto de normas contradictorias entre sí, de manera que postulemos que la discusión sobre los alcances del objeto contractual no quedó zanjada y, que en función de ello, si bien los contratos pueden presentar contenido obligacional, en rigor no lo demandan.

En esa discusión sobre los alcances del Código Civil (1984), más allá de nuestras propias convicciones, y de nuestro propio juicio sobre si la opción del codificador de 1984 respecto al objeto contractual fue la más adecuada, debemos actuar con eticidad. Esto quiere decir que no solo debemos respetar la opinión ajena, por más que pudiésemos considerarla equivocada, esto es, sin descalificarla por el solo hecho de que no coincida con la propia, sino también exponer los criterios interpretativos que existen, lo cual presupone enunciar los antecedentes de las normas y qué es lo que se representó el legislador al momento de la redacción final.

Dado que postulamos que el objeto de todo contrato, desde una óptica de funcionalidad normativa, es una obligación -como relación jurídica específica-, resulta pertinente destacar estos alcances.

En palabras de Díez-Picazo y Gullón (2013):

La obligación es una situación bipolar, que se encuentra formada, por un lado, por la posición de una persona llamada deudor, y por otro, por la posición de otra persona distinta llamada acreedor. El acreedor es titular de un derecho subjetivo (derecho de crédito), que 
le faculta para exigir frente al deudor lo que por éste es debido (prestación). Al mismo tiempo, como medida complementaria, el acreedor se ve investido de la posibilidad, en caso de incumplimiento, de proceder contra los bienes del deudor, así como investido también de una serie de facultades para la defensa de sus intereses. La segunda faceta o el segundo polo es la posición del deudor. El deudor es sujeto de un deber jurídico (deuda), que le impone la observancia del comportamiento debido y le sitúa en el trance de soportar, en otro caso, las consecuencias de su falta.

Como situación de dos polos, la "obligación" es una relación jurídica (relación obligatoria). La relación obligatoria es un cauce o un instrumento para que las personas puedan realizar actividades de cooperación social y, más concretamente, para que puedan intercambiar bienes y servicios. (p. 111)

Conforme a lo enunciado, y por las razones históricas expuestas al inicio de este trabajo, se puede sostener que la decisión del codificador nacional de regular un objeto contractual no fue una decisión accidental, sino que representó una determinada visión de la realidad y de la convivencia social.

No solo se genera una relación social, sino jurídica cuando finalmente se entrelazan dos personas en función de ciertas circunstancias reconocidas por el derecho, de las cuales se desprenden determinadas consecuencias (Roppo, 2009, pp. 36-37). Las relaciones jurídicas, desde dicha perspectiva, son necesariamente subjetivas, entre sujetos de derecho, con la representación de las consecuencias legales en caso de inobservancia; empero, pueden categorizarse bajo diversas modalidades (Breccia, Bigliazzi Geri, Natoli y Busnelli, 1992, pp. 351-357). Así, por ejemplo, no es lo mismo una relación poder-deber que una relación crédito-deuda. La primera está signada con una titularidad que puede ser opuesta a cualquier persona (erga omnes) de manera que toda persona (perteneciente al universo de aplicación del poder) debe respetarla. La segunda se caracteriza por una titularidad específica que solo puede ser opuesta a determinada persona inter partes, por lo que solo el deudor está sometido al respectivo acreedor, atendiendo a que este tiene un interés directo y exclusivo hacia él (Morales, 2008, pp. 356-359).

Un contrato, como expresión concreta del poder negocial que posee toda persona para acordar una determinada relación jurídica, de existir 
intereses relevantes o dignos de tutela ${ }^{13}$, implica que es el instrumento necesario para que una determinada persona pueda exigir algo a otra. Si bien el interés de una persona puede radicar en lograr una acción, o una abstención de otra, o la entrega de una determinada cosa, no es menos cierto que para poder exigirlo debe haber un determinado enlace. Por ello es que se sostiene que el objeto del contrato es obligacional, porque lo que se pretende jurídicamente (objeto) es crear (regular, modificar o extinguir) dicho enlace, a ello va encaminada la declaración de voluntad ${ }^{14}$ común.

La obligación emanada del contrato implica una determinada relación jurídica que deriva en situaciones subjetivas precisas para quienes por elemental relatividad contractual son las partes sustantivas o materiales del respectivo acuerdo: una de ellas (acreedor) asume la titularidad de una situación subjetiva de ventaja que es el crédito; y la otra (deudor), la situación subjetiva de desventaja que es la deuda o débito. Siendo que la relación obligacional presenta ambas situaciones, como anverso y reverso de una misma moneda, se entiende que el crédito permite al acreedor poder exigir al deudor, solo al deudor y a nadie más que al deudor (por el efecto relativo del vínculo), que realice cierta actividad, positiva o negativa, para satisfacer su interés, de manera que la asunción de la deuda está orientada exclusivamente a satisfacer dicho interés. Por ello es que, en caso de cumplimiento o pago, calificada doctrina (Hernández Moreno, 1983, pp. 75-86) señala que la ejecución cumple una doble funcionalidad: satisfactiva y extintiva. Lo primero está orientado netamente al interés del acreedor, y lo segundo a que, sobre la base de que el acreedor ya fue satisfecho en su interés, nada justifica la subsistencia de la vinculación, de manera que esta se extingue; el pago pone fin a la relación obligacional que fuese generada en su

13 Esto puede válidamente asociarse a la noción de causa negocial objetiva.

14 Resulta pertinente destacar que la declaración es precisamente una exteriorización de voluntad que persigue o pretende generar cierto efecto. En el marco de la autonomía privada, lo que pretenden las partes, a través de sus declaraciones coincidentes, es justamente un efecto: una relación jurídica vinculante, obligacional; de manera que ella sea el título sobre el cual pueda exigirse la prestación debida mediante la cual se satisface el interés del acreedor. Resulta interesante que, aunque puedan considerarse sinónimos, entre manifestación y declaración de voluntad se puede apreciar una fina y sutil diferencia jurídica. La declaración es una manifestación de voluntad, orientada voluntariamente para producir determinados efectos jurídicos. Un contrato demanda de declaración antes que de una simple manifestación de voluntad. 
momento por el contrato, aunque ambas funciones no operan necesariamente unidas, ya que pueden estar disociadas.

En realidad:

El pago, como efecto, es un concepto ambivalente. Su ambivalencia proviene de las distintas funciones que puede llevar a cabo. El Código Civil español establece en su art. 1.156 que "las obligaciones se extinguen $[\ldots]$ por el pago o cumplimiento [...]". He aquí su primera y más importante función. Parece, por tanto, que siempre que una obligación se pague o se cumpla, la deuda se extingue y el deudor queda liberado por la entrega de la cosa o el hecho de la prestación en que la obligación consistía. Hay, consiguientemente, una perfecta simetría entre la satisfacción del interés del acreedor, que ve realizado su crédito, y la liberación del deudor, que ve extinguida su deuda. [...]

Sin embargo, hay casos en los cuales la extinción de la obligación del deudor no viene dada como consecuencia de la satisfacción del interés del acreedor, sino más bien prescindiendo de la misma. [...]

Inversamente, cabe considerar igualmente algún caso en que la función satisfactiva del pago venga desligada de la función extintiva del mismo, pero ahora a expensas de esta última. (Hernández Moreno, 1983, pp. 75-86)

Debe destacarse que la objeción a la opción nacional sobre el objeto contractual obligacional no se limita a un simple tema de textualidad normativa (atendiendo a los alcances del artículo 1351 del Código Civil de 1984); también se sostiene (Gabrielli, 2013, p. 260) que el artículo 1402 del Código Civil peruano representa un error conceptual, al confundir lo que es el objeto del acto (del contrato) con el objeto de la relación (de la obligación) (Hernández, 1983, p. 75-81). Así, Gabrielli (2013) considera lo siguiente:

En el derecho latinoamericano del contrato, en general, el tema del contenido y del objeto ha sido codificado de forma distinta, según el tipo de planteamiento que los ordenamientos individuales han acogido, recibiendo las líneas guía ofrecidas por las experiencias jurídicas de los países europeos, o bien según cómo, en el transcurso del tiempo, han elaborado autónomamente la sistematización del hecho jurídico hipotético (fattispecie). 
Al describir el marco normativo, puede hacerse una primera clasificación entre los Códigos que contemplan una parte general sobre el acto o sobre el negocio jurídico y una parte especial sobre el contrato, y los códigos que, por el contrario -siguiendo el modelo del código italiano que, como es sabido, deriva su planteamiento del Code Napoleon- regulan solamente la parte sobre el contrato en general.

Por ejemplo, en la primera categoría se ubica el Código Civil peruano, el cual -en su última formulación- contiene una norma en materia de acto jurídico y un específico título en materia de objeto del contrato (art. 1402, Cód. Civ.), en el cual, no obstante (cuando se dice que "el objeto del contrato consiste en crear, regular, modificar o extinguir obligaciones"), se comete un error conceptual al confundir el objeto del acto (esto es, del contrato) con el objeto de la relación (esto es, la obligación). (pp. 259-260)

Es más, en nuestro medio, el profesor Lizardo Taboada Córdova (1992) postuló, desde una perspectiva dogmática, que los artículos 1402 y 1403 responden a una determinada visión desde un cuestionable enfoque propio del derecho de contratos, mas no desde la rigurosidad abstracta de la teoría del negocio jurídico. El autor destaca, por un lado, que la definición del objeto contractual es errada porque la relación obligatoria es la consecuencia de la celebración del contrato, por lo que no puede ser su objeto; dado que por este último puede entenderse en doctrina tanto un elemento, presupuesto o requisito (tema estructural). De otro lado, considera que se trata de una definición que juzgaba innecesaria, porque debería estarse al objeto del negocio jurídico, puesto que un contrato es una especie de dicho género, sin perjuicio de que estimara innecesario que se incorporen definiciones en un cuerpo legislativo.

Pero, ante dichos cuestionamientos, no debe olvidarse que se está ante una obra legislativa y que muchos de sus contenidos corresponden a opciones normativas con una determinada finalidad, siendo esto último lo que debe prevalecer para fines de interpretación.

Si entendemos que el acto jurídico es el contrato mismo, lo que se busca con este es definitivamente generar una determinada relación jurídica, de contenido obligacional, conforme con los artículos 1351, 1402 y 1403 del Código Civil peruano (1984), alcanzado el respectivo acuerdo. Lo que subsiste es la relación jurídica (más allá de que sea de ejecución inmediata e instantánea, o diferida), la cual versa sobre una determinada conducta positiva o negativa que puede ser exigida por el 
acreedor al deudor, y radica en la prestación debida para fines de que el acreedor adquiera los beneficios correspondientes que le permitan satisfacer su interés. Recordemos que objeto tiene varias acepciones en nuestro idioma. Literalmente, es objeto contractual tanto lo que se pretende (la relación jurídica obligacional) como el bien o servicio sobre el cual recae finalmente el interés del acreedor. El objeto contractual peruano no es estrictamente la prestación, ni los bienes o servicios sobre los que recae esta última (recordemos lo concerniente al lenguaje corriente). El objeto contractual peruano es la relación obligacional, porque el contrato como hecho (no como norma, no como documento) genera, vía consentimiento, la respectiva relación jurídica, y con ello cumple su único cometido (Ferri, 2004, pp. xliv-xlvi).

En palabras de Larroumet (1999), resulta pertinente considerar lo siguiente:

El encuentro de las voluntades de las partes contratantes tiene por objeto vincularlas jurídicamente, esto es, crear obligaciones. [...] Sin embargo, es preciso tener en cuenta que el contrato a veces puede tener por objeto constituir un derecho real o transferir un derecho o una obligación. En realidad, el objeto del contrato se confunde con su efecto.

El Código Civil ${ }^{15}$ no distingue entre el objeto del contrato y el objeto de la obligación, creada por el contrato.

Algunos autores critican este método y se proponen distinguir entre el objeto del contrato y el objeto de la obligación. Mientras que el objeto de la obligación es la prestación que el deudor debe cumplir [...], el objeto del contrato estaría constituido por la operación jurídica contemplada en su conjunto [...]. El objeto del contrato será su contenido económico, tal como lo han querido las partes ${ }^{16}$.

Pero el problema consiste en saber cuál es la utilidad de la noción de objeto del contrato, considerada independientemente del objeto de determinada obligación originada por el contrato. Se pretende

15 Se refiere al Código Civil francés. Téngase presente que el Código Civil peruano sí hace la diferencia.

16 Entendemos que ese contenido económico no radica sino en el propósito para fines del tráfico o intercambio económico de bienes y servicios, lo cual se alcanza mediante la respectiva relación jurídica de contenido obligacional, que permite poder exigir cierta conducta, en el marco de la relatividad, para satisfacer los intereses económicos comprometidos. 
que se trata de someter el contrato al control del juez, quien verificará si la operación está conforme con el orden público y con las buenas costumbres. $[\ldots]^{17}$

No obstante, recurrir a la noción de objeto del contrato es inútil, porque el control del juez, en cuanto a la conformidad del contrato con el orden público y con las buenas costumbres, se ejercerá, sea por la vía del objeto de la obligación creada por el contrato, sea mediante la noción de causa ${ }^{18}$.

$[\ldots]$

[...] la idea del fin perseguido, que supone que se busquen las razones del acuerdo de voluntades, es ajena al objeto, mientras que realmente constituye el meollo de la noción de causa del contrato. La causa del contrato permite al juez ejercer un control sobre la moralidad del contrato y sobre su licitud por la vía del fin perseguido, sin que haya lugar a tener en cuenta el objeto de las obligaciones creadas. Este objeto puede ser perfectamente neutral y, por consiguiente, válido, lo cual no impedirá considerar al contrato como ilícito o inmoral en función del fin que debe alcanzar por el acuerdo de voluntades.

En resumidas cuentas, el objeto del contrato puede aparecer como una complicación inútil. Es el objeto de la obligación lo que es oportuno considerar ${ }^{19}$. (pp. 286-289)

17 La referida adecuación es para fines de evitar la generación del objeto ilícito (contravención de normas imperativas), prohibido (contravención del orden público) e inmoral (contravención de las buenas costumbres), esto es, en general, de lo que podemos denominar objeto antijurídico o en contravención al ordenamiento.

18 La noción de causa subjetiva es distinta de la de causa objetiva; el tema motivacional es independiente del propósito negocial relevante, digno de tutela y protección para el ordenamiento jurídico, en función mediata del interés social comprometido.

19 Estimamos que no hay tal complicación, y que sí se justifica la noción de objeto contractual. Si asumimos que el contrato tiene como propósito la creación consensuada de una determinada relación jurídica, perfeccionado constitutivamente solo subsiste esa relación jurídica. Eso es lo que pretenden las partes. Otro tema es que la relación jurídica obligacional constituida pretende obtener la ejecución de una prestación o conducta debida, para alcanzar finalmente un bien o servicio, una cosa en sentido general. Lo más cómodo es identificar los requisitos de la prestación y de la cosa misma, pero ello no significa obviar que ellos representan el interés mediato de las partes, el efecto o consecuencia que se desprende de haberse configurado la relación jurídica sin la cual no sería posible 
En síntesis, para fines del tráfico o intercambio de bienes y servicios, las partes contratan. Con ello, únicamente instituyen relaciones jurídicas específicas, obligacionales, sujetas al principio de relatividad (los efectos directos que se desprenden de ellas solo comprometen a las partes, centros de interés afectados por su celebración, no a terceros). Creada la obligación (interés abstracto del acreedor), el contrato alcanza su finalidad existencial $\mathrm{y}$, en consecuencia, se extingue. Es en función del vínculo generado que puede exigirse la conducta debida (o producirse, ministerio legis), lo cual permitirá satisfacer el interés concreto del acreedor.

Por ello, puede postularse que el objeto contractual inmediato o abstracto es la obligación, siendo que la prestación sobre la cual versa está orientada a lograr la consecución de la cosa, que es el objeto mediato o concreto, porque si bien uno puede teorizar sobre qué es lo que se proponen las partes al contratar, no puede obviarse que, más allá de la explicación académica, en el entendimiento ordinario lo que se pretende es obtener un bien o servicio.

\section{Conclusión}

En el presente trabajo se ha pretendido exponer en función de qué corresponde interpretar las reglas del Código Civil peruano en materia de objeto contractual, con el consiguiente impacto en el régimen de transferencia convencional de propiedad, en particular, la inmueble (artículo 949 del Código Civil); pero también creemos que no puede negarse que la redacción del Código Civil de 1984 no es precisamente la más feliz e invita a varias lecturas. Y, desde el momento en que hay una pluralidad de posibles interpretaciones, pueden generarse pronunciamientos judiciales disímiles por completo ${ }^{20}$, y eso quiebra toda predictibilidad y seguridad jurídica. Ahí radica la trascendencia del tema.

Postulamos que del texto del Código Civil de 1984, y de sus propios antecedentes que permiten explicarlo, el entendimiento del codifica-

exigir lo debido. En otras palabras, si bien el objeto contractual puede parecer de contenido abstracto, al igual que su característica que es la licitud o adecuación al ordenamiento, no por ello deja de ser un concepto necesario para poder alcanzar el propósito mediato o concreto de las partes, que a través de la conducta debida se tenga acceso al bien o servicio comprometido.

20 La manera en que entendamos transferida la propiedad, un derecho real por excelencia, con vocación de oponibilidad absoluta, va a tener una incidencia directa en el régimen de las tercerías excluyentes de propiedad, por ejemplo. 
dor fue uno solo, hubo una determinada opción legislativa y creemos que está allí la clave del asunto: el artículo 1402 del Código Civil, conforme con el cual se define imperativamente que los contratos son obligacionales. En consecuencia, no puede sustentarse legislativamente una eficacia contractual real, y menos puede sostenerse que los codificadores de derechos reales y de obligaciones y contratos tuvieron lecturas contrapuestas.

Sin embargo, retomando lo ya manifestado sobre el lenguaje legislativo, resulta seguramente conveniente una adecuación de textos, pero considerando siempre un elemental criterio de sistematicidad, ya que la transferencia de propiedad derivada parte de la premisa de que hay un contrato, siendo que el legislador se preocupó expresamente en definir el objeto contractual para evitar discusiones e interpretaciones disímiles.

En síntesis, sostenemos que en esta materia no es suficiente " $[\ldots]$ tomar una actitud más positiva e intentar la interpretación de la norma cuestionada utilizando especialmente los medios o elementos lógico y sistemático, para otorgarle su verdadero sentido a través de su relación con las demás en su conjunto" (De la Puente y Lavalle, 2011, p. 668), sino que por la trascendencia económica del tema debería replantearse tanto la redacción del artículo 1351 como la del propio artículo 949 del Código Civil, en términos tales que no generen dudas sobre sus alcances $^{21}$. Quizá ya haya llegado el momento de retomar la propuesta de clasificación legal de los bienes en función de su situación registral, y de manera correlativa de cómo entender que se transfieren constitutivamente. Si admitimos que el lenguaje legislativo debe ser preciso, las sutilezas de las interpretaciones académicas no contribuyen precisamente a que todos tengan la misma representación sobre en qué momento se adquiere la propiedad inmueble.

21 “La actual redacción del artículo 949 del Código Civil ha dado lugar a que la doctrina peruana se encuentre dividida en dos sectores: uno de ellos opina que el sistema peruano de adquisición de la propiedad está articulado en la aplicación de la teoría del título y el modo para el caso de los bienes muebles y la aplicación del principio de la transmisión solo consensu para el caso de los bienes inmuebles; el otro sector sostiene que tanto para el caso de los bienes muebles como para el de los bienes inmuebles debe aplicarse la teoría del título y el modo" (De la Puente y Lavalle, 1999, p. 23). 


\section{Referencias}

Alterini, J. H., Corna, P. M., Angelani, E. B., y Vásquez, G. A. (2000). Teoría general de las ineficacias. Buenos Aires, Argentina: La Ley.

Arias-Schreiber, M. (1995). Exégesis del Código Civil peruano de 1984 (tomo I: Contratos: Parte general, con la colaboración de Carlos Cárdenas Quirós, Ángela Arias-Schreiber M., y Elvira Martínez Coco). Lima, Perú: Gaceta Jurídica Editores.

Bianca, M. (1994). El interés (traducción libre a cargo del profesor Gastón Fernández, de la parte pertinente del libro Diritto civile, volumen 4: L'obbligazione). Ius et Veritas, 5(9), 111-115.

Breccia, U., Bigliazzi Geri, L., Natoli, U., y Busnelli, F. (1992). Derecho civil (tomo I, volumen 1: Normas, sujetos y relación jurídica, 1. ${ }^{\mathrm{a}}$ ed.). Bogotá, Colombia: Universidad Externado de Colombia.

Comisión Reformadora. Decreto Supremo 95. (1 de marzo de 1965). Lima, Perú: Congreso de la República.

Comisión Revisora. Ley 23403. (mayo, 1982). Lima, Perú: Congreso de la República.

De la Puente y Lavalle, M. (2011). El contrato en general. Comentarios a la Sección Primera del Libro VII del Código Civil (tomos II y III, 2. ${ }^{\text {a ed.). }}$ Lima, Perú: Palestra Editores.

De la Puente y Lavalle, M. (1999). Estudios sobre el contrato de compraventa (1. ${ }^{\mathrm{a}}$ ed.). Lima, Perú: Gaceta Jurídica Editores.

Díez-Picazo, L., y Gullón, A. (2013). Sistema de derecho civil (volumen II, tomo 1: El contrato en general. La relación obligatoria, 10. ${ }^{a}$ ed.). Madrid, España: Tecnos.

Espinoza Espinoza, J. (2008). Acto jurídico negocial. Análisis doctrinario, legislativo y jurisprudencial (1. ${ }^{a}$ ed.). Lima, Perú: Gaceta Jurídica Editores.

Ferri, L. (2004). Lecciones sobre el contrato. Curso de derecho civil (Presentación, notas y edición a cargo de Rómulo Morales Hervias y Leysser León, 1. ${ }^{a}$ ed.). Lima, Perú: Grijley.

Gabrielli, E. (2013). Estudios sobre teoría general del contrato (Traducción, revisión y notas al cuidado de Rómulo Morales Hervias y Walter Vásquez Rebaza). Lima, Perú: Jurista Editores.

Hernández Moreno, A. (1983). El pago del tercero. Barcelona, España: Bosch. 
Larroumet, C. (1999). Teoría general del contrato (volumen I). Bogotá, Colombia: Temis.

Morales Hervias, R. (2008). Situaciones jurídicas subjetivas. Advocatus, 19, 323-360.

Moreyra García-Sayán, F. (2005). El acto jurídico según el Código Civil peruano. Curso teórico, histórico y comparativo. Lima, Perú: Fondo Editorial de la Pontificia Universidad Católica del Perú.

Proyecto de la Comisión Reformadora. (1981). Lima, Perú: Congreso de la República.

Proyecto de la Comisión Revisora. (1984). Lima, Perú: Congreso de la República.

Real Academia Española. (2014). Diccionario de la lengua española. Recuperado de http://lema.rae.es/drae/

Roppo, V. (2009). El contrato (1. ${ }^{a}$ ed.). Lima, Perú: Gaceta Jurídica Editores.

Taboada Córdova, L. (1992). La problemática del objeto del negocio jurídico. Ius et Veritas, 3(5), 53-60. 
